\title{
Anaphoric demonstratives in multimodal communication
}

\author{
Nikolaeva Ju. V. \\ MSU \\ julianikk@gmail.com
}

\author{
Evdokimova A. A. \\ Institute of Linguistics, \\ RAS \\ arochka@gmail.com
}

\author{
Budennaya E. V. \\ Higher School of Economics \\ Institute of Linguistics, RAS \\ jane.sdrv@gmail.com
}

\begin{abstract}
The paper explores how anaphoric demonstratives interact with concomitant manual and cephalic gestures on the material of the RUPEX multimodal corpus. The analysis established a number of correlations between the speaker's role in the communication episode and his verbal and non-verbal behavior. It was found that Reteller who has not seen the film tends to use more anaphoric demonstratives than the Narrator. This may be explained by the Reteller's aim to establish discourse coherence when reconstructing the story, as far as by his responsibility to the Listener who will subsequently record the retelling of what he heard without the opportunity to ask additional questions. In addition, manual channel has shown that demonstrative units are more often accompanied by depictive rather than by pointing gestures which may be due to their anaphoric nature. No similar tendency was detected in the cephalic channel where anaphoric demonstratives were covered by pointing gestures. Moreover, in the manual channel, the introduction of demonstrative words correlated with CVPT gestures, but only in monologues, while cephalic viewpoint was more complex. The multichannel approach allows one to notice discourse features that are not directly expressed in any of the communication channels, but are deduced from their combination.
\end{abstract}

Keywords: demonstrative, anaphora, hand gesture, head gesture, multimodal communication

DOI: $10.28995 / 2075-7182-2021-20-1130-1143$

\section{Указательная анафора в мультимодальной коммуникации}

\author{
Николаева Ю. В. \\ МГУ \\ julianikk@gmail.com
}

\author{
Евдокимова А. А. \\ Институт \\ языкознания РАН \\ arochka@gmail.com
}

\author{
Буденная Е. В. \\ НИУ ВШЭ/ Институт \\ языкознания РАН \\ jane.sdrvegmail.com
}

\begin{abstract}
Аннотация
Статья посвящена взаимодействию анафорических указательных выражений с параллельными жестами рук и головы на материале мультимодального корпуса RUPEX. Анализ выявил ряд корреляций между ролью говорящего (Рассказчик / Пересказчик / Комментатор) и его невербальным поведением. Было обнаружено, что Пересказчик, не видевший фильма, чаще прибегал к указательной анафоре, по сравнению с Рассказчиком. По-видимому, данными действиями Пересказчик стремился воссоздать дополнительную связность нарратива - как для себя самого, так и для Слушателя, который в дальнейшем, в соответствии с дизайном эксперимента, должен письменно пересказать услышанное от Пересказчика, без возможности задавания каких-либо дополнительных вопросов. Кроме того, сопоставительный мультимодальный анализ показал, что анафорические указательные выражения чаще сопровождались указательными жестами головы и изобразительными жестами рук. Данная особенность может объясняться их ситуационно анафорическим, а не дейктическим характером. Также при сопоставлении каналов было выявлено, что жесты головы вели себя не идентичным образом, по сравнению с жестами рук, что отразилось в разном наборе типов жестов, соотношением жестов в монологических и диалогических фрагментах и в невербальной коммуникации с точки зрения персонажа и наблюдателя. В мануальном канале указательные выражения преимущественно сопровождались жестами персонажа на монологических фрагментах, а в цефалическом канале набор жестов на монологических и диалогических фрагментах отличался. Таким образом, мультиканальный подход позволил выявить ряд специфических дискурсивных особенностей, отраженных в непосредственном сочетании нескольких каналов коммуникации.

Ключевые слова: указательное местоимение, указательное наречие, анафора, жесты головы, жесты рук,
\end{abstract} мультимодальная коммуникация 


\section{1 Введение. Мультимодальная коммуникация как средство изучения языка}

Человеческая коммуникация представляет собой сложное взаимодействие вербальных и невербальных явлений. Долгое время объектом языковых исследований являлся исключительно вербальный компонент, однако развитие мультимодальной лингвистики, с созданием размеченных мультиканальных корпусов, позволило изучать язык в более полной перспективе. В частности, стало возможным совместное исследование вербального канала и параллельной жестикуляции на большом корпусе данных; многие вопросы, необъяснимые без учета невербальной составляющей, стали доступны для изучения (обзор и конкретные примеры см., в частности, [Kress, van Leeuwen 2001; LeVine, Scollon 2004; Kibrik, Podlesskaya 2009; Mondada 2016; Perniss 2018]). Tем не менее возможности мультимодальной лингвистики по-прежнему оставляют большой простор для исследований. В частности, перспективным является изучение языковых явлений в зависимости от типа коммуникации (монолог vs. диалог) и роли говорящего: ряд исследований отразил нетривиальную связь этих факторов с дистрибуцией различных вербальных, просодических и кинетических маркеров [Podlesskaya et al. 2019; Korotaev 2019a; Budennaya et al. 2020].

Настоящая статья посвящена изучению русских указательных местоимений и наречий в анафорическом употреблении в сопоставлении с параллельными жестами рук и головы. Несмотря на то, что дейксис и анафора широко изучались в лингвистике с различных позиций [Lyons 1977; Anderson, Keenan 1985, Himmelmann 1996; Levinson 2004, Diessel 2006, Kibrik 2011], в том числе и в контексте мультимодальной коммуникации [Strauss 2002; Enfield 2003; Nikolaeva 2004; Stukenbrock 2015; Grishina 2017], объектом мультимодальных исследований, в первую очередь, был первичный дейксис, ориентированный на непосредственную ситуацию речевого акта (1). Так, при сопоставлении вербального и кинетических каналов (в число последних входят жесты рук и головы, а также мимика, направление взгляда, движения корпуса и ног, т.е. все движения тела) основное внимание уделялось поиску соответствий между указательными жестами и дейктическими именными группами [Diessel 2006, Grishina 2017, Levinson 2018], тогда как указательные местоимения и наречия во вторичном анафорическом употреблении (2) в мультимодальных исследованиях изучались крайне фрагментарно. Эти два типа контекстов для указательных жестов также называют, соответственно, конкретным (1) и абстрактным указанием (2) [McNeill 1992].

(1) - Посмотри на эту девочку! (говорящий показывает на конкретную девочку)

(2) Вчера я видел девочку. Этой девочке было лет семь.

Данная работа ставит своей целью восполнить этот пробел и рассмотреть на корпусном материале все типы жестов головы и рук (т.е. жесты цефалического и мануального кинетических каналов) в контексте сопутствующих вербальных единиц, а именно - абстрактных указаний типа (2).

Материалом работы является мультиканальный корпус RUPEX («Рассказы и разговоры о грушах», подробнее см. сайт проекта_www.multidiscourse.ru и [Kibrik 2018]). Для исследования указательной анафоры был выбран так называемый эталонный подкорпус - записи \#04, \#22, \#23, в состав каждой входит 10 медиафалов, из которых 3 - индивидуальные видео, таким образом общая длительность изученных видео составила около трех часов. Каждая запись состоит из 4 этапов: 1) Рассказчик (далее N) и Комментатор (далее C) молча смотрят «Фильм о грушах» [Chafe 1980]; 2) N рассказывает сюжет фильма для Пересказчика (далее R), который фильма не видел; 3) разговор между N, C и R, где C дополняет рассказ N, a R имеет возможность задать вопросы; 4) по итогам разговора R пересказывает сюжет фильма для Слушателя (далее L), который присоединяется непосредственно на последнем этапе. После этого L записывает сюжет фильма на основе монолога R. Общий дизайн коммуникативной ситуации представлен на Рис. 1. 


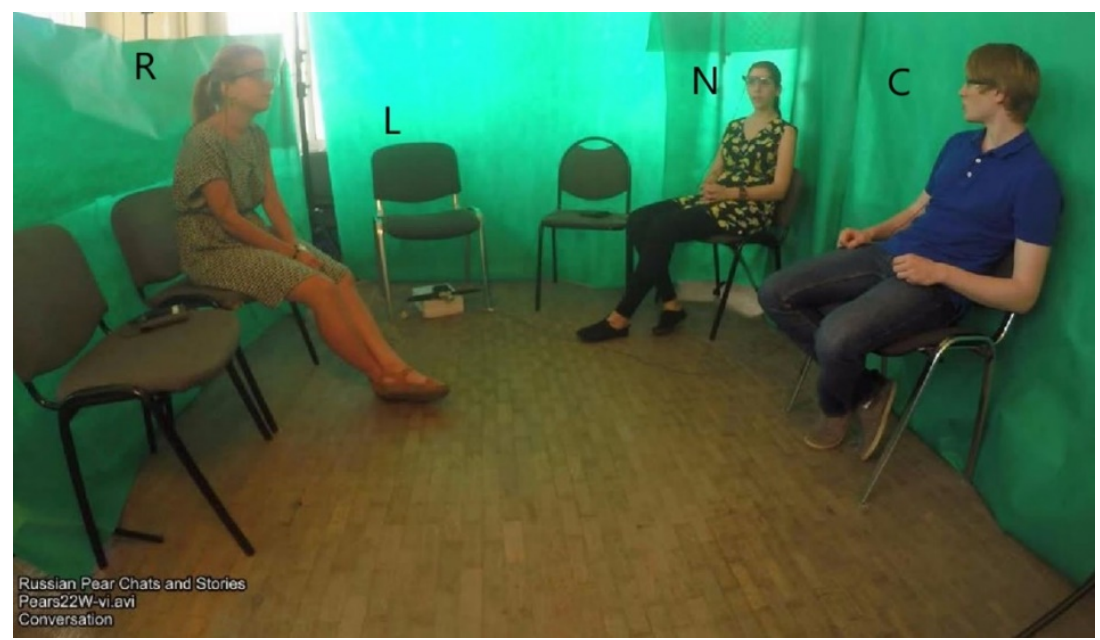

Рис. 1: Расположение и роли участников записи

Статья построена следующим образом. В разделе 2 даются основные сведения об указательных местоимениях и наречиях, представленных в корпусе RUPEX, и рассматривается их дистрибуция в зависимости от роли говорящего (Рассказчик, Пересказчик, Комментатор). В разделе 3 формулируются общие принципы подхода к анализу невербальных каналов. Разделы 4 и 5 посвящены мануальным и цефалическим жестам и их непосредственному взаимодействию с вербальным компонентом.

\section{2 Указательные местоимения и наречия в корпусе RUPEX}

B вербальном канале RUPEX встретились следующие типы указательных единиц ${ }^{1}$ :

- $\quad$ Указательные местоимения в самостоятельном употреблении (далее Dem):

(3) Pears04:
R-vE489² ${ }^{2}$ Возвращает ему /шляпп,
R-vE490 a /тот ему /взамен три \груши даёт.

- Указательные местоимения в качестве атрибута именной группы (далее $D e m N$ ):

(4) Pears04:
R-vE212 И он видит что нет /
$\mathrm{R}-\mathrm{vE2} 13$ и /дальше проходят эти

(5) Pears22:
R-vE225 /они идут тоже с /грушами,
R-vE226 и-и \едят эти /груши,

\footnotetext{
${ }^{1}$ В работе не учитывались омонимичные указательным наречиям дискурсивные маркеры препаративной подстановки типа это, это самое и частица там в роли маркера “несущественной детали”, омонимичная соответствующему наречию [Shmelev 2007; Kibrik, Podlesskaya 2009].

2 Здесь и далее в корпусных примерах код отражает участника (N/C/R), тип файла и номер строки в транскрипте, подробнее о вокальной аннотации см. [Korotaev 2019b]
} 
- Указательные наречия (далее $D e m A d v)$ :

(6) Pears23:
N-vE227 Он поднял /штаны,
N-vE228 и там были Ггольфы,

В силу специфики материала (участники коммуникации не имели перед глазами непосредственных реферируемых объектов), указательные средства использовались говорящими в непрямом дейктическом употреблении (преимущественно указательные наречия) и в качестве анафорических выражений (самостоятельные и атрибутивные указательные местоимения). Дистрибуция всех указательных средств представлена в Табл. 1.

\begin{tabular}{|c|c|c|c|c|c|c|c|c|c|c|}
\hline & \multicolumn{3}{|l|}{ \#04 } & \multicolumn{3}{|l|}{ \#22 } & \multicolumn{3}{|l|}{ \#23 } & SUM \\
\hline & $\mathrm{N}$ & $\mathrm{C}$ & $\mathrm{R}$ & $\mathrm{N}$ & $\mathrm{C}$ & $\mathrm{R}$ & $\mathrm{N}$ & $\mathrm{C}$ & $\mathrm{R}$ & \\
\hline Dem & 1 & 1 & 1 & 2 & 4 & 1 & 0 & 0 & 1 & 11 \\
\hline DemN & 6 & 2 & 11 & 3 & 14 & 9 & 2 & 5 & 15 & 67 \\
\hline DemAdv & 7 & 6 & 8 & 7 & 4 & 3 & 16 & 6 & 10 & 67 \\
\hline TOTAL & 14 & 9 & 20 & 12 & 20 & 13 & 18 & 11 & 26 & 145 \\
\hline
\end{tabular}

Таблица 1: Дистрибуция указательных местоимений и наречий в эталонном подкорпусе RUPEX

Наименее частотными в корпусе оказались анафорические указательные местоимения в самостоятельном употреблении, что объясняется их более маркированной семантикой и дискурсивными особенностями (контрастивность, антецедент в непосредственно предшествующей клаузе в неподлежащной позиции, меньшая активированность и актуализированность референта в дискурсе [Kibrik 2011: 328 и след.]). Связь с ролью говорящего для данного типа местоимений обнаружена не была - возможно, в связи с крайне малым количеством данных. Иные закономерности были выявлены в распределении указательных наречий и именных групп с атрибутивными местоимениями. Так, несмотря на приблизительно равное соотношение в выборке в целом (Табл. 1), на этапе монолога (средняя продолжительность - около пяти минут для всех говорящих) Пересказчики значимо чаще (точный тест Фишера, p-value $<0.05$ ) прибегали к именным группам с указательными местоимениями, по сравнению с Рассказчиками (Рис. 2), а также использовали более разнообразный инвентарь указательных наречий (Рис. 3).

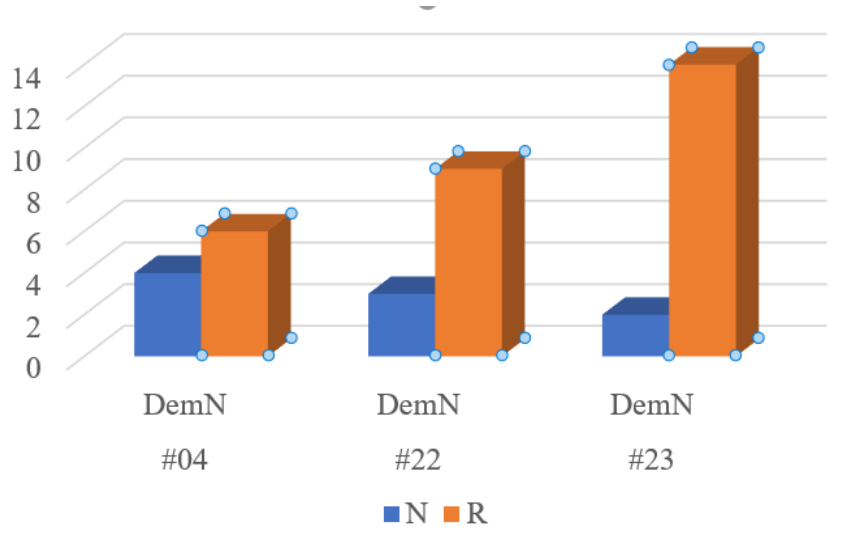

Рис. 2: Дистрибуция именных групп с атрибутивным указательным местоимением у Рассказчиков и Пересказчиков RUPEX 


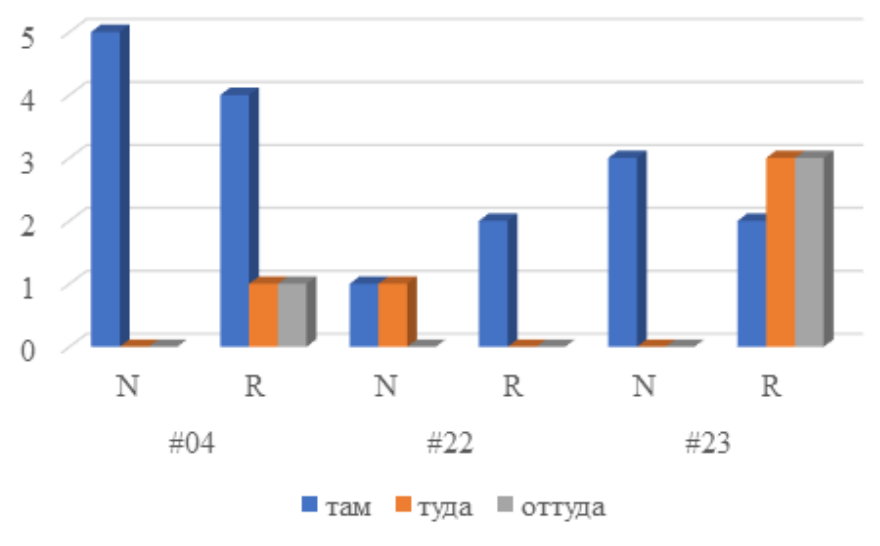

Рис. 3. Типы указательных наречий, употребляемых Рассказчиками и Пересказчиками RUPEX.

Более высокое соотношение именных групп с атрибутивными указательными местоимениями Пересказчиков (Рис. 2) может обусловливаться семантикой $D e m N$, непосредственно связанной с дизайном ситуации. Так, известно, что анафорические $D e m N$ с ближними демонстративами типа этот по сравнении со стандартными именными группами обладают дополнительной модифицирующей семантикой, позволяющей более четко идентифицировать референта [Maes, Noordman 1995; Cornish 2007]. В частности, в (4) элемент эти мальчики позволяет Слушателю более четко соотнести соответствующее выражение с ранее упомянутым антецедентом, тогда как без указательного местоимения данная группа формально может обозначать любых мальчиков вообще, в силу чего идентификация их с конкретными ранее упомянутыми мальчиками потребует от Слушателя больших ментальных усилий. Можно предположить, что R обладает в некотором смысле большей ответственностью перед своим Слушателем L, который далее будет записывать сюжет фильма только на основе монолога $\mathrm{R}$, не имея возможности задать дополнительные вопросы. В связи с этим R в большей мере стремится эксплицировать референтов для $\mathrm{L}$, по сравнению с N, который, в свою очередь, не стремится лишний раз дополнительно конкретизировать референтов, поскольку заранее знает, что после его рассказа предстоит еще этап разговора, на котором R сможет задать любые уточняющие вопросы.

Кроме того, можно полагать, что во время своего монолога для Слушателя Пересказчик также стремится дополнительно реконституировать повествовательную линию фильма для себя самого, поскольку строит рассказ исключительно на сведениях, полученных от N и С. Насыщение монолога R именными группами и указательными наречиями, дополнительно эксплицирующими референтов и их локацию, способствует в этом случае поддержания связности.

\section{3 Невербальные каналы: принципы анализа}

\section{1 Жесты головы и рук в RUPEX}

Для анализа были использованы аннотации жестов рук и головы (мануальных и цефалических), выполненные по принципам, изложенным для описания движений головы в [Sukhova, Evdokimova 2021, in press] и для рук в [Litvinenko et al. 2018], на материале трех записей \#22, \#23, \#4. При сопоставлении ЭДЕ (элементарных дискурсивных единиц, определяемых на основе просодических признаков и в прототипическом случае соответствующих синтаксической клаузе) и жестов в качестве основного брался вербальный канал, т.е. ЭДЕ. В тех случаях, когда одной ЭДЕ соответствовало больше одного жеста рук, выбирался тот жест, который в наибольшей степени соответствовал содержанию слов (таким образом, не рассматривались менее содержательные биты или прагматические жесты, если в той же ЭДЕ был указательный или, тем более, изобразительный жест). Случаев семантического рассогласования выбранного жеста и соответствующей по времени ЭДЕ в данной выборке не встретилось. Жесты головы заметно короче, чем жесты рук, и на одну ЭДЕ приходится в среднем от 2 до 5 цефалических жестов, при подсчетах жесты с одинаковыми функциями на одной ЭДЕ суммировались. 
В рамках ЭДЕ с указательными местоимениями и наречиям рассматривались мануальные и цефалические жесты и их функции (указательная, изобразительная, прагматическая для обоих каналов, ритмическая для рук и регуляторная для головы). При определении типов жестов головы учитывались также принципы, изложенные в [Grishina 2017], предполагающие сочетание прагматических и указательных функций в одном движении. Направление и тип движения учитывались только для движений головы (поворот, кивок, наклон и др.) и только в качестве уточнения взаимоотношений в рамках зон коммуникации (см. Раздел 3.2.).

Для жестов рук учитывалось только поведение говорящих, а для жестов головы также поведение слушающих.

Для движений рук учитывалась точка зрения (viewpoint) жестикулирующего: в случае жестов с точки зрения персонажа (CVPT) говорящий двигается так же, как один из участников ролика; если жест выполнен с точки зрения наблюдателя (OVPT), то участники описываемой сцены как бы располагаются перед жестикулирующим на экране. По некоторым данным, жесты с точки зрения персонажа иллюстрируют события, более важные для понимания сюжета [McNeill 1992] или более выделяющиеся в дискурсе [Parrill 2010]; в других исследованиях [Beattie, Shovelton 2002] было показано, что жесты с точки зрения персонажа передают больше информации адресату.

\section{2 Зоны коммуникации в жестах головы}

Жесты головы и рук существенно отличаются, одно из основных различий состоит в том, что жесты рук предполагаются только у говорящего, в то время как у слушающего они встречаются крайне редко. При этом движения головы - один из основных каналов, с помощью которых слушающий может дать обратную связь говорящему (яркий пример - академический кивок). Кроме того, движения головы выполняют важную регуляторную и интерактивную функции, показывая, например, к кому обращается говорящий и чьей реплики ожидает слушающий. Движения головы гораздо короче по времени, чем жесты рук, и их число в корпусе RUPEX на порядок больше.

Так как жесты головы часто в том числе указывают на жесты, происходящие в других кинетических каналах, например, руках, то при анализе и интерпретации типов цефалических жестов мы учитывали изменения границ между тремя зонами, описанными E.A. Гришиной [Grishina 2017: 129]: зоной видимости (“объект зрительно доступен говорящему”), невидимой зоной (“объект зрительно недоступен говорящему”) и зоной коммуникации (“пространство между говорящим и слушающим; объект зрительно доступен и говорящему, и слушающему”). Под объектом для жестов головы мы понимали в том числе и жесты других кинетических каналов, происходящие в этих зонах.

Поскольку в дизайне RUPEX у каждого участника несколько зон коммуникации (см. рис. 5, черным обозначена зона коммуникации N-C, белым - N-R, синим - C-R), при анализе жестов головы мы учитывали, как сменяются зоны коммуникации и как идет обмен жестами в разных зонах. Такой принцип позволял оценивать не только сами движения и их направление, но и их соотнесенность с жестами других участников. 


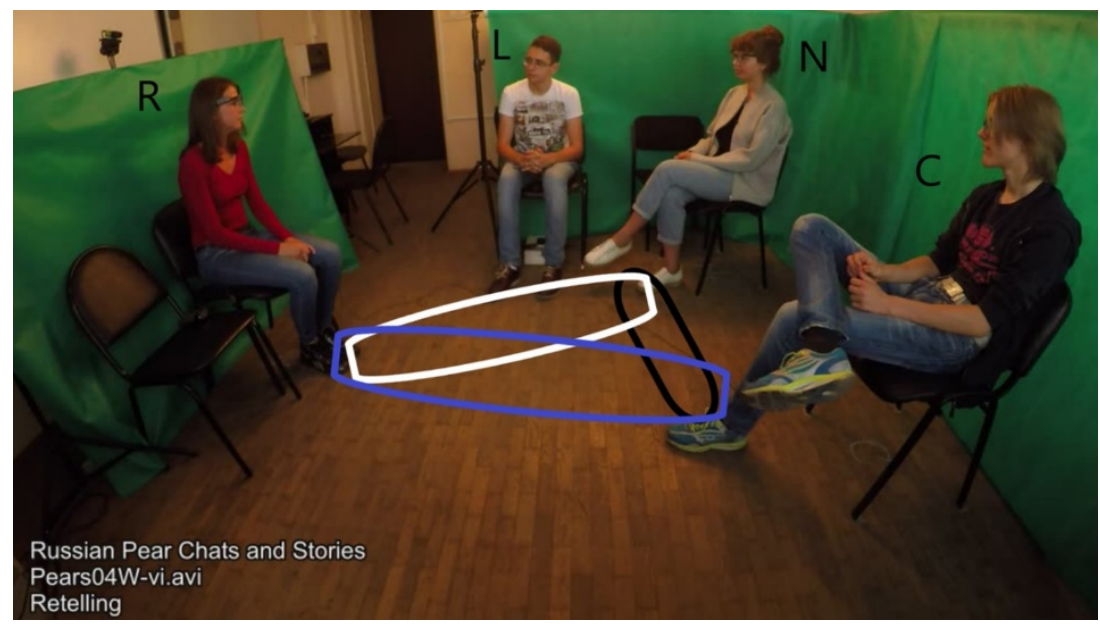

Рис. 4: Зоны коммуникации трех участников записи

\section{4 Невербальные каналы: принципы анализа}

Анализ мануальных жестов с указательными местоимениями и наречиями показал, что на ЭДЕ с такими словами возрастает количество изобразительных жестов в большей степени, чем указательных $(\chi$-квадрат, p-value $<0.01)$, при уменьшении числа прагматических жестов (см. Табл. 2 и Рис. 5).

\begin{tabular}{|l|l|l|l|l|}
\hline Типы жестов & \multicolumn{2}{|l|}{ Всех жестов } & \multicolumn{2}{l|}{ Жестов в указ. } \\
выборке
\end{tabular}

Таблица 2: Мануальные жесты с указательными местоимениями.

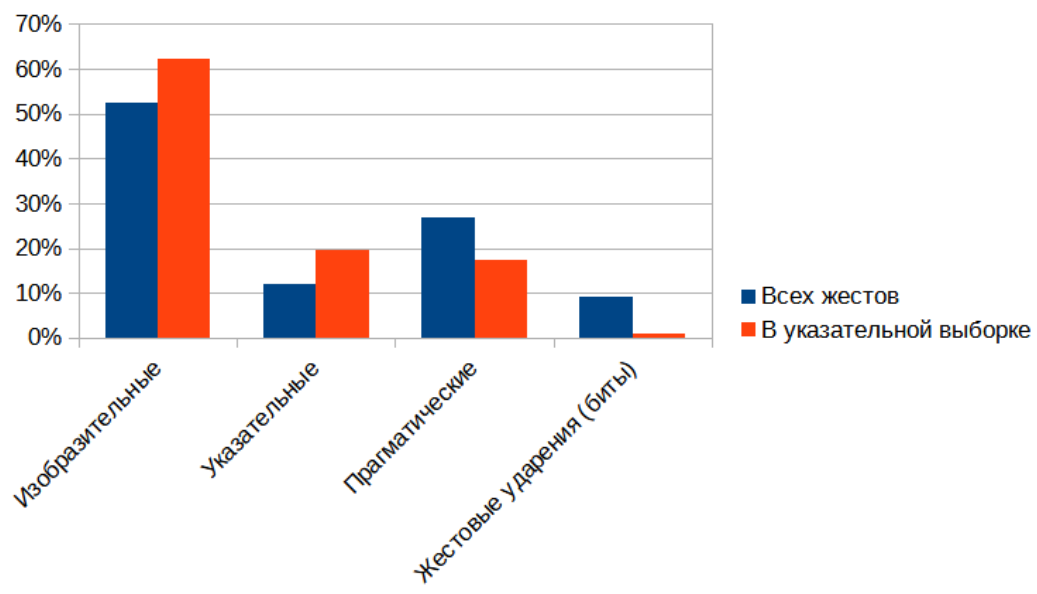

Рис. 5: Мануальные жесты с указательными местоимениями (\%) 
Показательно, что увеличение изобразительных жестов на указательных словах зависит от роли участника (см. Рис. 6).

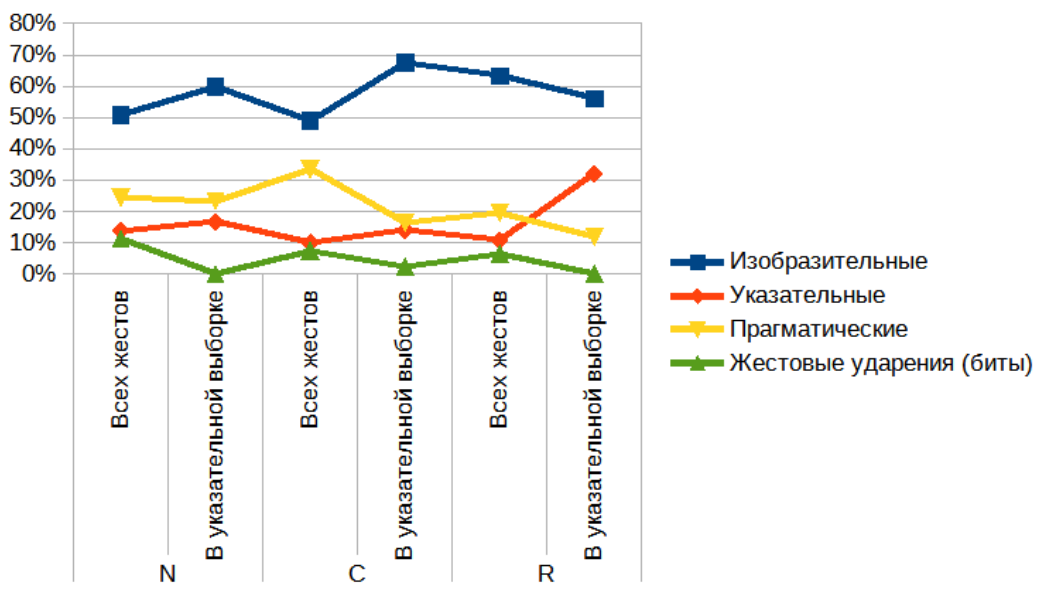

Рис. 6. Типы жестов с указательными местоимениями в зависимости от роли участника (\%)

Можно видеть, что у Комментатора изобразительные жесты нарастают на указательных местоимениях в большей степени, чем у Рассказчика, а у Пересказчика они, наоборот, уменьшаются.

Возможные объяснения этому факту состоят в следующем:

1. Различие между $\mathrm{N}$ и $\mathrm{C}$, с одной стороны, и R, с другой стороны, может быть связано с тем, что $\mathrm{R}$ не видел фильм и поэтому знает меньше подробностей об обсуждаемом сюжете. Изобразительные жесты часто не просто дублируют, но и сообщают некоторую дополнительную информацию, не выраженную в словах, позволяющую полнее представить действия персонажей, их взаимное положение и движение и свойства объектов.

2. Различие между $\mathrm{N}$ и $\mathrm{C}$, которые видели фильм, и $\mathrm{R}$, который узнал о сюжете от первых двух участников, может быть объяснено целями дискурсивной связности: указательные слова служат для поддержания локальной и референциальной связности, и обращение Пересказчика к пространству для описания сопутствующих событий может быть вспомогательным средством, служащим для поддержания вербальных референциальных средств (кто куда поехал или пошел, где располагались референты, где происходило действие очередного эпизода).

3. Кроме этого, жестикуляция на таких фрагментах может служить целям $\mathrm{R}$ в рамках записи: передача адресату (L) как можно больше подробностей фильма, про который $\mathrm{R}$ узнал из чужого рассказа и может описать меньше подробностей, удобных для передачи изобразительными жестами, но может в качестве компенсации прибегнуть к иллюстрации с помощью менее содержательных жестовых указаний.

4. Еще одно объяснение исходит из того, что жестикуляция, сопровождающая речь, по некоторым данным облегчает нагрузку на рабочую память. Пересказчик должен восстановить в памяти события, о которых он слышал от других, и заполнить пробелы, возникшие оттого, что какая-то информация была забыта или не была упомянута. «Отслеживание» положения и перемещений референтов с помощью жестов создает таким образом визуальное подкрепление для решения этих задач.

Наконец, если посмотреть, как меняется точка зрения (персонажа или наблюдателя) в изобразительных жестах рук с указательными словами на фоне остальных данных (Табл. 3, Рис. 7), можно видеть, что в целом на указательных словах точка зрения персонажа (CVPT, которую связывают, в частности, с большей важностью фрагмента или большей вовлеченностью говорящего в описываемые события) встречается чаще, чем в среднем, и это особенно заметно для $\mathrm{C}$ и $\mathrm{R}$ $(\chi$-квадрат, $\mathrm{p}$-value $<0.01)$. 


\begin{tabular}{|c|c|c|c|c|c|c|c|c|c|}
\hline & \multicolumn{3}{|l|}{$\mathrm{N}$} & \multicolumn{3}{|l|}{ C } & \multicolumn{3}{|l|}{$\mathrm{R}$} \\
\hline & \multicolumn{2}{|c|}{$\begin{array}{l}\text { с указательными } \\
\text { словами }\end{array}$} & \multirow{2}{*}{$\begin{array}{l}\text { со всеми } \\
\text { ЭДЕ } \\
55 \% \\
\end{array}$} & \multicolumn{2}{|c|}{$\begin{array}{l}\text { с указательными } \\
\text { словами }\end{array}$} & \multirow{2}{*}{$\begin{array}{l}\text { со всеми } \\
\text { ЭДЕ } \\
\\
76 \%\end{array}$} & \multicolumn{2}{|c|}{$\begin{array}{l}\text { с указательными } \\
\text { словами }\end{array}$} & \multirow{2}{*}{$\begin{array}{l}\text { со всеми } \\
\text { ЭДЕ } \\
\\
54 \%\end{array}$} \\
\hline 己 & 11 & $61 \%$ & & 11 & $79 \%$ & & 22 & $76 \%$ & \\
\hline 8 & 7 & $39 \%$ & $45 \%$ & 3 & $21 \%$ & $24 \%$ & 7 & $24 \%$ & $46 \%$ \\
\hline & 18 & $100 \%$ & $100 \%$ & 14 & $100 \%$ & $100 \%$ & 29 & $100 \%$ & $100 \%$ \\
\hline
\end{tabular}

Таблица 3: Точка зрения в изобразительных жестах рук на всех ЭДЕ и только с указательными словами

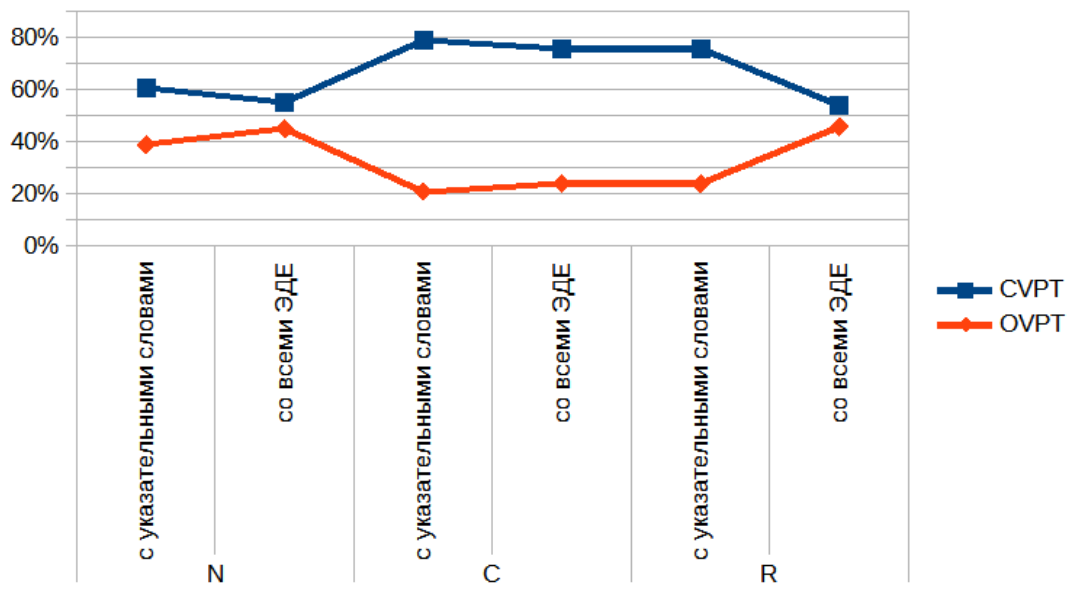

Рис. 7: Точка зрения в изобразительных жестах на всех ЭДЕ и только с указательными словами (\%)

Таким образом, можно сделать вывод, что ЭДЕ с указательными словами в анафорическом употреблении отличаются тем, что для них еще чаще, чем в среднем по корпусу, будут встречаться изобразительные жесты (по крайней мере для двух из трех участников каждой записи), и эти жесты с большей вероятностью будут от лица персонажа, причем эта тенденция особенно заметна для С. Как уже упоминалось выше, такой перекос в зависимости от роли может быть вызван когнитивной функцией жестов (облегчение нагрузки на рабочую память и упрощение вербализации пространственно-динамической информации), целями дискурсивной связности или задачами говорящего в рамках его фиксированной роли в данной записи.

\section{5 Цефалические жесты с указательными словами}

При анализе разбираемых ЭДЕ в эталонном подкорпусе RUPEX было выявлено 132 жеста головы у говорящих, которые распределились по типам следующим образом : указательные $-71,96 \%$ ( $\chi$-квадрат, p-value $<0.001$ ), указательно-прагматические - 18,18\% (например, указательные на жесты рук) и прагматические жесты, разделяющиеся на Pragmatic-center - 4,54\% и Pragmatic-away $3,78 \%$ которые содержат косвенное указание, (см. [Evdokimova 2020]), а также изобразительные - 1,51\%, образующие кинетический кластер с жестами рук [Nikolaeva, Evdokimova 2020]. Кроме того, жесты головы могли участвовать в указательных кластерах с жестами рук, дублируя направление жеста и тип движения. 
Учитывание изменения границ зон коммуникации показало, что почти все участники, независимо от их роли перед указательными ЭДЕ использовали регуляторные жесты головы, тем самым выделяя и предвосхищая указательные единицы.

Как выяснилось в ходе исследования, указательные единицы (местоимения и наречия) по-разному сопровождаются жестами головы. При качественном анализе было выявлено, что жесты головы, маркирующие указательные наречия (Рис. 8), адресуют слушающего к пространству событий из мира дискурса, которое в ситуации разговора находится в невидимой зоне, т.е. за спиной или сбоку от говорящего (см. Раздел 3), а те цефалические жесты, которые появляются с указательными местоимениями (Рис. 9), направлены в общее жестовое пространство перед собеседниками и чаще всего на жесты рук. Поэтому в случае наречий наблюдается смена направления жестов головы, а в случае указательных местоимений создается общая зона коммуникации для всех участников.

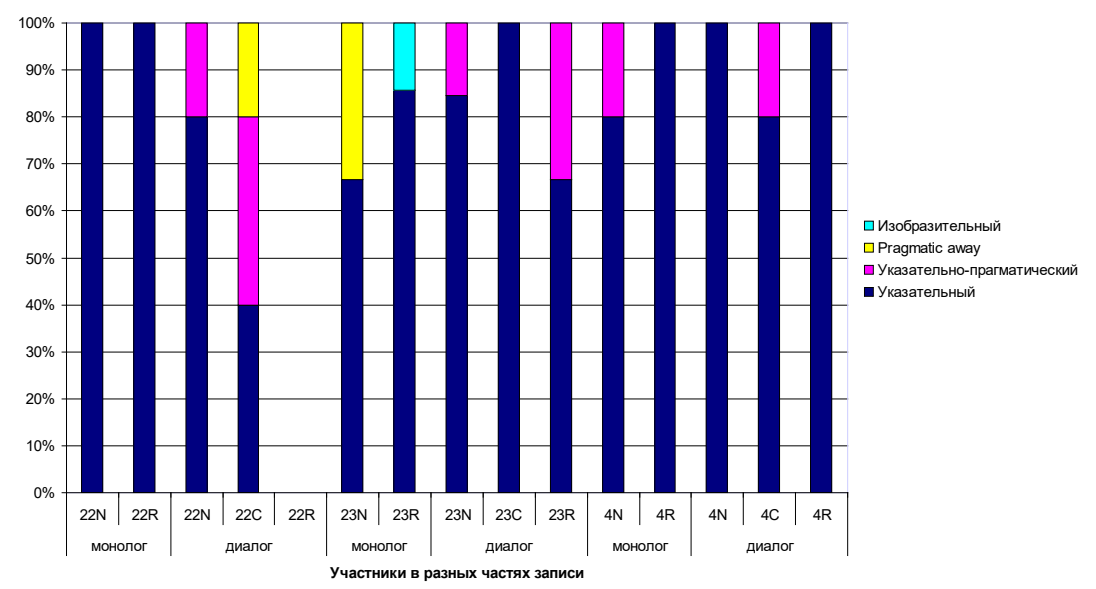

Рис. 8: Типы жестов головы в монологе и диалоге на ЭДЕ с указательными наречиями

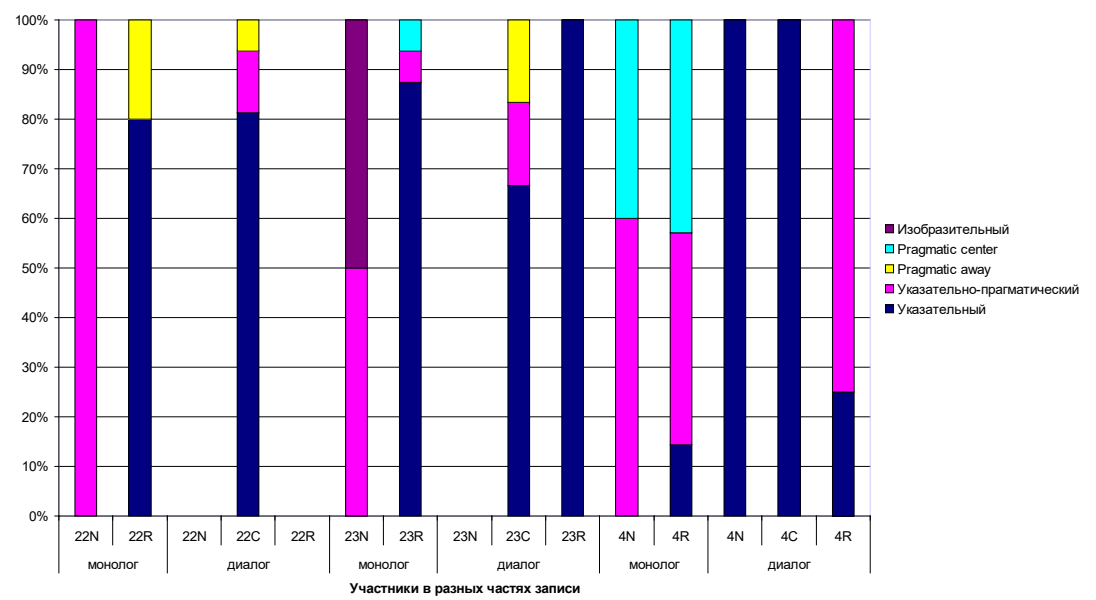

Рис. 9: Типы жестов головы в монологе и диалоге на ЭДЕ с указательными местоимениями

Кроме этого, жесты головы зависят от роли участника и от того, встретилась данная единица в монологической или диалогической части. У всех $\mathrm{N}$ представлено большее разнообразие типов цефалических жестов, чем у всех $\mathrm{C}$ и $\mathrm{R}$, но в диалогической части $\mathrm{N}$ и $\mathrm{R}$ используют меньше разных типов жестов, чем С, см. Рис. 10 и Рис. 11. 


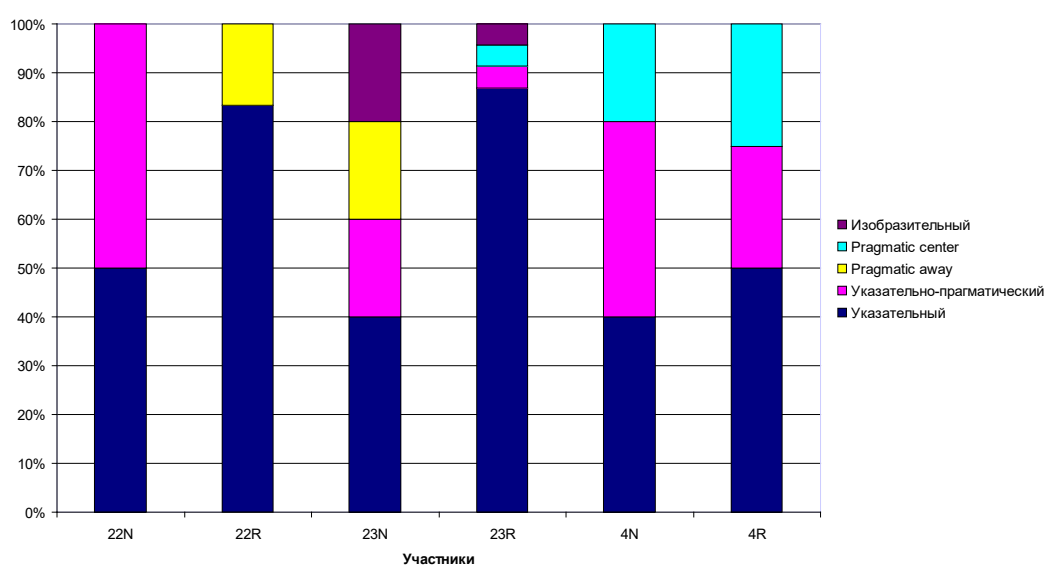

Рис. 10: Типы жестов головы в монологе

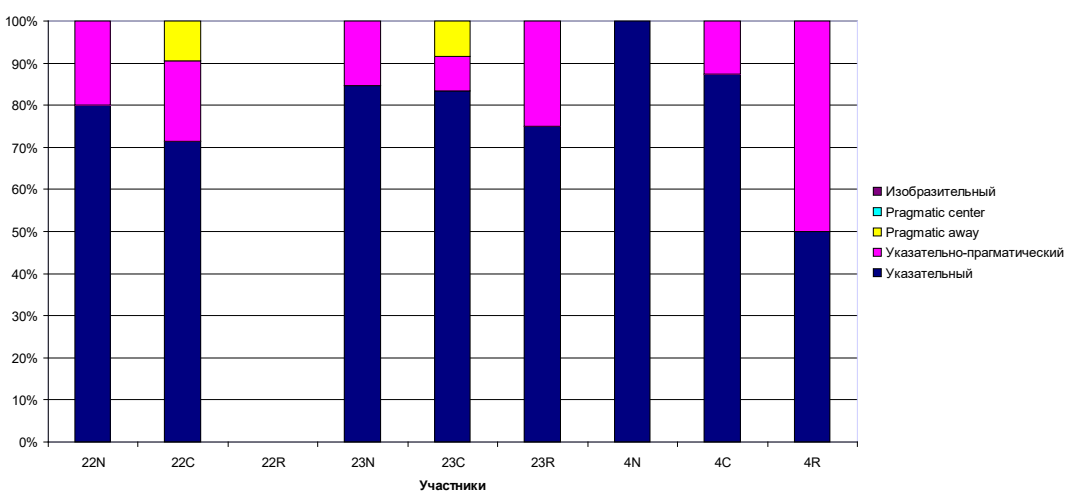

Рис. 11. Типы жестов головы в диалоге

Это сопоставимо с тем, что изобразительные мануальные жесты на изучаемых вербальных единицах также присутствуют чаще у $\mathrm{N}$ и $\mathrm{R}$, чем у C.

Наличие изобразительных кластеров жестов головы и рук у Рассказчика и Пересказчика, показанных с точки зрения персонажа, в сопоставлении с кластерами указательных жестов с точки зрения наблюдателя у Комментатора, совпадает с наблюдениями в мануальном канале в разделе 4.

Для верификации, насколько выявленные тенденции зависели от жестового портрета испытуемых, были также проанализированы их жесты головы, возникающие, как реакции на указательные ЭДЕ других участников, всего было выявлено таких 124 жеста. При сопоставлении типов жестов, у тех же участников, когда они слушали, было выявлено явное преобладание прагматических $(\chi$-квадрат, p-value $<0.001)$ и регуляторных жестов ( $\chi$-квадрат, p-value $<0.001)$, а также большая вариативность жестов у тех участников, которые фильм видели, то есть у Рассказчика и Комментатора (см. Рис. 12). Поскольку выявленные на примере 22 записи (Табл. 4) соотношения были подтверждены и 23 , и 4 записью, мы можем утверждать, что выявленные тенденции определялись ролями испытуемых в большей степени, чем их жестовыми портретами. 


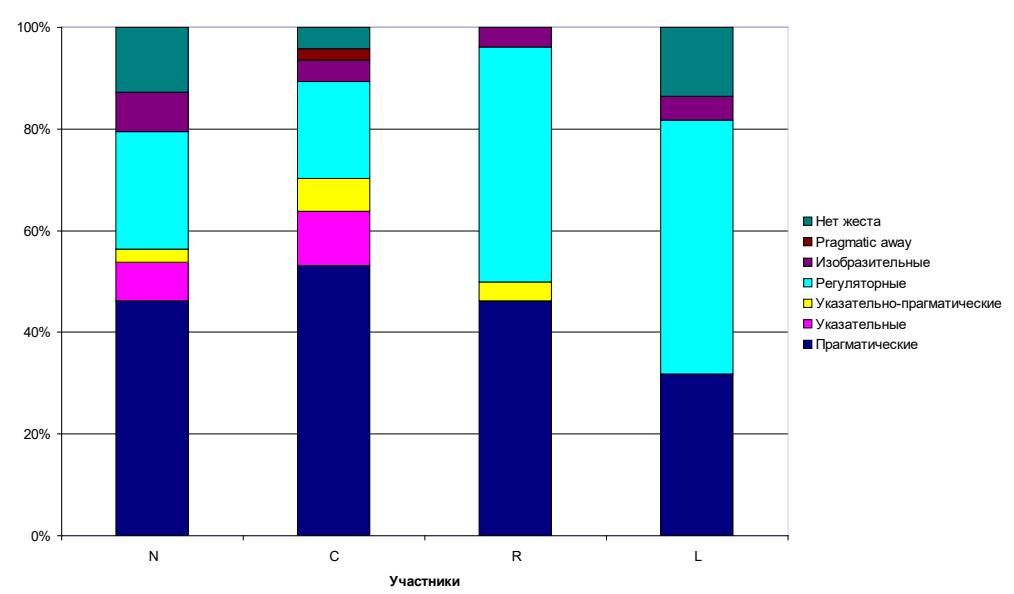

Рис. 12. Типы жестов головы у разных участников в роли слушающего

\begin{tabular}{|l|l|l|l|l|l|l|}
\hline & \multicolumn{5}{|l|}{$\begin{array}{l}\text { участник в роли го- } \\
\text { ворящего }\end{array}$} & \multicolumn{4}{l|}{ участник в роли } \\
& слушаюего
\end{tabular}

Таблица 4: Типы жестов головы в зависимости от роли участника (говорящий или слушающий) на примере 22 записи

Кроме того, по данным анализа в 22 записи встретилось три повтора ЭДЕ с указательным наречием у Рассказчика (N-vE176, N-vE182), и с указательными местоимениями у Комментатора (C-vE079, C-vE105) и Пересказчика (R-vE200, R-vE226). На этих повторных последовательных ЭДЕ в мануальном канале встретились одинаковые изобразительные жесты, тогда как в цефалическом канале набор жестов отличался -- на повторном ЭДЕ жесты изменяли функцию с указательной на указательно-прагматическую или же исключительно прагматическую. Разница цефалического жестового поведения в этих фрагментах также подтверждалась разницей в реакциях слушателей. По этим данным можно видеть, что жесты рук в рассматриваемых ЭДЕ в большей степени отражали семантику высказывания, тогда как жесты головы преимущественно отвечали за регулировку коммуникации. Данные наблюдения объясняют преобладание указательных жестов головы на разбираемых ЭДЕ у говорящих и прагматических и регуляторных у слушающих, а также преобладание изобразительных жестов рук вместо ожидаемого увеличения указательных. 


\section{6 Заключение}

В ходе корпусного мультимодального анализа указательных анафорических местоимений и наречий был выявлен ряд нетривиальных закономерностей, отражающих связь с ролью говорящего и его жестикуляцией, а также его взаимодействие с другими собеседниками. В частности, в вербальном канале было обнаружено, что Пересказчик, не видевший фильм, чаще прибегает к эксплицирующим именным группам с указательными местоимениями, чем Рассказчик. Это может объясняться, помимо очевидной анафорической функции, предполагающей более быструю идентификацию референта, желанием воссоздать связность нарратива (Пересказчик строит свой рассказ исключительно на фрагментарных сведениях других участников), а также большей ответственностью перед Слушателем, который в дальнейшем будет записывать пересказ услышанного без возможности задать дополнительные вопросы. Кроме того, у Пересказчика на ЭДЕ с анафорическими словами было больше указательных жестов, что также можно объяснить с точки зрения воссоздания связности нарратива. Также в мануальном канале появление указательных слов в ЭДЕ у Рассказчика и Комментатора коррелировало с большей вероятностью жеста персонажа.

Анализ кинетических каналов показал, что для участников, видевших фильм, указательные выражения чаще сопровождаются изобразительными, чем указательными мануальными жестами. Хотя в целом изобразительные жесты в этом корпусе составляют половину или чуть больше мануальных жестов, в указательной выборке их доля становится еще больше и достигает $80 \%$ у некоторых говорящих. Это может объясняться тем, что рассмотренные единицы представляют собой анафору (а не дейксис, как в других исследованиях о сочетании указательных слов и жестов). Как было показано в других работах, изобразительные жесты связывают с тем, что иллюстрируемые ими события отличаются большей важностью в рассказе. В связи с этим можно сделать вывод о дискурсивной выделенности ЭДЕ с анафорическими указательными словами в таких пересказах.

Помимо этого, было обнаружено, что цефалический канал передает сходные, но не идентичные мануальным значения. Одна из тенденций, зафиксированных в цефалическом канале, заключалась в большем разнообразии движений головы на монологических фрагментах по сравнению с диалогическими. Для жестов головы значимым оказался тип указательной единицы: все участники независимо от роли маркировали указательные наречия указательными жестами, адресующими слушающего к пространству событий из мира дискурса, которое в ситуации разговора находится за спиной или сбоку от говорящего, а указательные местоимения сопровождались жестами головы, направленными в общее жестовое пространство перед собеседниками, и чаще всего на жесты рук, среди которых, в свою очередь, в данной выборке выросло число изобразительных. Таким образом, можно наблюдать сложное взаимодействие трех каналов: указательные слова в вербальном сопровождаются изобразительными жестами рук (которые подробно описывают те же события) и эти же слова подчеркнуты указательными жестами головы.

\section{References}

[1] Anderson S. R., Keenan E. L. Deixis, Language typology and syntactic description. Cambridge: Cambridge University Press, 1985. - Vol. 3, Grammatical categories and the lexicon. — P. 259-308.

[2] Beattie G., Shovelton H. An experimental investigation of some properties of individual iconic gestures that mediate their communicative power // British Journal of Psychology 93. — 2002. — P. 179-192

[3] Budennaya E.V., Nikolaeva Ju.V., Evdokimova A.A., Sukhova N.V. (2020), Referential phenomena in speaker's kinetic channels, Computational Linguistics and Intellectual Technologies. Proceedings of the International Conference "Dialog 2020" [Komp'yuternaya Lingvistika i Intellektual'nye Tekhnologii: Trudy Mezhdunarodnoy Konferentsii "Dialog 2020"], RGGU, pp. 133-146.

[4] Chafe W. The pear stories: cognitive, cultural, and linguistic aspects of narrative production, NJ, Norwood: Ablex, 1980.

[5] Cornish F. English demonstratives: discourse deixis and anaphora. A discourse-pragmatic account // Interpreting utterances: Pragmatics and its interfaces. Essays in honour of Thorstein Fretheim. Oslo: Novus Press, 2007. - P. 147-166.

[6] Diessel H. Demonstratives, joint attention, and the emergence of grammar // Cognitive Linguistics 17. 2006. - P. 463-489.

[7] Enfield N. Demonstratives in space and interaction: data from Lao speakers and implications for semantic analysis // Language 79. - 2003. - P. 82-117. 
[8] Evdokimova A.A. (2020) Pragmatic center and Pragmatic away: new types of pragmatic head gestures. [Novye tipy pragmaticheskih zhestov golovy — Pragmatic center i Pragmatic away], Linguistika i metodika prepodavaniya inostrannyx jazykov [Linguistics and Language Teaching], Vol. 1 (12), pp. 136-148.

[9] Grishina E. A. (2017), Russian gesticulation from a linguistic perspective (corpus studies) [Russkaja zhestikuljacija s lingvisticheskoj tochki zrenija (korpusnyje issledovanija)], Moscow: LRC Publishing House.

[10] Himmelmann N. Demonstratives in narrative discourse: A taxonomy of universal uses. // Studies in Anaphora. John Benjamins, Amsterdam, pp. 205-254.

[11] Kibrik A. A., Podlesskaja V. I. (eds.) (2009), Night Dream Stories: A corpus study of spoken Russian discourse [Rasskazy o snovidenijax: Korpusnoe issledovanie ustnogo russkogo diskursa], Moscow: LRC.

[12] Kibrik A. A. Reference in discourse, Oxford: Oxford University Press, 2011.

[13] Kibrik A. A. (2018). Russian multimodal corpus. Part II. Development of the corpus and research topics [Russkiy multikanal'niy discurs. Chast' II. Razrabotka korpusa i napravleniya issledovaniy], Journal of Psychology [Psikhologicheskiy zhurnal], Vol. 39 (2), pp. 79-90.

[14] Korotaev N. A. (2019a), Hesitation pauses in narratives and conversations: A quantitative comparison [Pausy xesitacii v rasskaze i v razgovore], Proceedings of the Corpus Linguistics Conference 2019, [Trudy mezhdunarodnoj konferencii "Korpusnaja lingvistika-2019"], Saint Petersburg University, pp. 48-54.

[15] Korotaev N.A. "Russian Pear Chats and Stories": Vocal annotation guide, Version 10.01.2019. — 2019b. — URL: http://multidiscourse.ru

[16] Kress G., van Leeuwen T. Multimodal discourse. The modes and media of contemporary communication, London: Arnold, 2001.

[17] Levinson S. C. Introduction: Demonstratives: Patterns in diversity. Cambridge: Cambridge University Press, 2018. - P. 97-121.

[18] LeVine P., Scollon R. (eds.) Discourse and technology: multimodal discourse analysis, Washington, DC: Georgetown University Press, 2004.

[19] Litvinenko A. O., Kibrik A. A., Fedorova O. V., Nikolaeva J. V. (2018), Annotating hand movements in multichannel discourse: Gestures, adaptors and manual postures // Russian Journal of Cognitive Science, Vol. 5 (2), pp. 4-17.

[20] Lyons J. Deixis and anaphora. The development of conversation and discourse, UK, Edinburgh: Edinburgh University Press, 1979. - P. 88-103.

[21] Maes A. A., Noordman L. G. M. Demonstrative nominal anaphors: a case of nonidentificational markedness // Linguistics 33 - 1995. - P. 255-282.

[22] McNeill D. Hand and mind: What gestures reveal about thought, IL, Chicago: University of Chicago Press, 1992.

[23] Mondada L. Challenges of multimodality: Language and the body in social interaction // Journal of Sociolinguistics, Vol. 20 (2) - 2016. - P. 2-32.

[24] Nikolaeva Ju. V. (2004), Functional and semantic aspects of illustrative gestures in Russian spoken discourse [Funktsional'nye i semanticheskie osobennosti illyustrativnykh zhestov v ustnoy rechi (na materiale russkogo yazyka)], Issues of General Linguistics [Voprosy yazykoznania] 4, pp. 48-64

[25] Nikolaeva Ju. V., Evdokimova A. A. (2020), Kinetic clusters and their functional types [Kineticheskie klastery i ix funkcional'nye tipy], Word and gesture. Proceedings of the conference [Slovo i zhest. Materialy konferencii], pp. 17-18.

[26] Parrill F. (2010), The hands are part of the package: Gesture, common ground, and information packaging, Empirical and Experimental Methods in Cognitive and Functional Research, CSLI, Stanford, pp. 285-302.

[27] Podlesskaja V. I., Kibrik A. A. (2009), Diskursivnye markery v structure ustnogo rasskaza: opyt korpusnogo issledovanija [The role of discourse markers in local discourse structure: a corpus study], Computational Linguistics and Intellectual Technologies. Proceedings of the International Conference "Dialog 2009" [Komp'yuternaya Lingvistika i Intellektual'nye Tekhnologii: Trudy Mezhdunarodnoy Konferentsii “Dialog 2009"], Bekasovo, pp. 390-395.

[28] Podlesskaja V. I., Korotaev N. A., Mazurina S. I. (2019), A corpus study of self-repairs in Russian monologues and dialogues [Samoispravlenija govorjashchego v russkom monologicheskom i dialogicheskom diskurse: opyt korpusnogo issledovanija], Computational Linguistics and Intellectual Technologies. Proceedings of the International Conference "Dialog 2020” [Komp'yuternaya Lingvistika i Intellektual'nye Tekhnologii: Trudy Mezhdunarodnoy Konferentsii “Dialog 2020”], RGGU, pp. 508-522.

[29] Perniss P. Why the study of language should be multimodal // Frontiers in Psychology 9 - 2018. - 1109.

[30] Shmelev A. (2007), Particle tam as marker of an unimportant detail [Chastitsa tam kak marker nesushchestvennoj detali], Language as a matter of meaning. Festschrift in honor of N.Yu. Shvedova [Jazyk kak materija smysla: sbornik statej k 90-letiju akademika N. Ju. Shvedovoj], Moscow: Azbukovnik, pp. 208-218.

[31] Strauss S. This, that, and it in spoken American English: a demonstrative system of gradient focus // Language Science 24. - 2002. - P. 131-152.

[32] Stukenbrock A. Deixis in der face-to-face-Interaktion, Berlin: Mouton de Gruyter, 2002.

[33] Sukhova N. V., Evdokimova A. A., Cephalic Annotation Scheme. The MCD handbook: A practical guide to annotating multichannel discourse. - 2021. To appear. 